\title{
On implementation of tasks of the National technological initiative
}

\author{
Natalia Yaskova ${ }^{1,2, *}$ \\ ${ }^{1}$ Russian Presidential Academy of National Economy and Public Administration, 29337, Vernadskiy \\ avnue, 84, Moscow, Russia \\ ${ }^{2}$ Moscow State University of Civil Engineering, 129337, Yaroslavskoye shosse, 26, Moscow, \\ 129337, Russia
}

\begin{abstract}
Transformation of the Russian economy is connected with technological renewal of all components of the national economics. Accelerating processes of technological renewal is now connected with implementation of the Program "National technological initiative". Best innovations of the national origin that have strategic superiority on the global markets are concentrated in this Program. The essence of the road maps in each of the global directions is a translation of requests from the leaders of the new technological markets into the system of public administration. Matrixes of the National technological initiative have been developed in order to capitalize scientific advances and creation of conditions for their practical implementation with preservation of the priority positions of the Russian companies of the created global markets. They link design and development with available resources, as well as with the legal and regulatory framework and stimuli of introduction. Basic technological package analyzed in its development is supposed not only to accelerate activities of companies of the Russian origin, but also create conditions for responses to the global challenges of science. In this regard, the article presents the main steps to ensure the practical implementation of the main directions of the National technological initiative. The analysis of matrixes demonstrated necessity of supplementing them with the project pool on the elimination of infrastructure wear and tear that would provide complex solution of the task of the full-scale implementation of the development potential of Russia.
\end{abstract}

\section{Introduction}

The uniqueness of the current position of Russia is the fact that de facto it is the undisputed international leader but in the end its geopolitical results are in contradictions with the accumulated economic problems. Practice has shown that contemporary Russia has gone far away the framework of the row materials periphery. With acceptance of the long-term complex program "National technological initiative" [1] the goals of the country received

\footnotetext{
*Corresponding author: mcua3@yandex.ru
} 
orientation towards new high-tech global markets, that have a network nature and substantially decrease distances between producers and consumers, as well as are focused on the needs of a man as a final consumer. The Program as a whole is directed to the increase of quality of life of a man by the development of sectors of the new technological order subject to ensuring national security and financial sovereignty of the country.

\section{Materials and methods}

The program "National technological initiative" started in 2016 that is in the period of the developing global technological revolution. Explosive development, implementation and dissemination of new technologies in all spheres of human activities lead at the moment to fast changes on the global markets, in industrial production and in economics. There appeared fundamentally new technological solutions, products and services. Within the next 10-20 years, it is expected to form completely new large markets, capable to satisfy growing needs of the global economy $[2,3]$. For contemporary Russia, which possesses innovation advance and necessary intellectual potential, the segment of new technological markets is becoming one of the priorities of its development. The country's enclosure into formation of standards of global markets of the future also becomes a key for obtaining a significant share for the Russian companies on these markets [4].

Coalition principles and methods that are focused on formation of groups of adherents representing technological entrepreneurs, representatives of leading universities and research centers, large business associations of Russia, institutes of development, expert and professional communities, as well as interested bodies of the executive power became the basis of the National technological initiative as one of the priorities of the state policy. The Program forms new and strengthens existing projects supporting scientific and technological development, providing translation of requests from the potential leaders of new markets into the system of public administration. For these purposes, workforces have been formed for each of the market directions that are headed by the established technological entrepreneurs, professionals in respective fields, and vice-ministers of respective federal ministries of the executive power. Interested representatives of business, scientific and educational communities, related bodies of the executive authority, etc. have been also integrated in the workforces. To these days, 12 such workforces have been created and are operational. "Road maps" for nine prospective markets and three cross-market directions have been developed [5]. As documents of the strategic planning with the complex of activities interlinked in tasks, time of implementation, implementing parties and resources, "road maps" are focused on creation, development and introduction into practice of new technologies, products and services, providing the following:

Firstly, priority positions of the Russian companies on the forming markets;

Secondly, improvement of the legislation and regulatory framework for liquidation of barriers for utilization of the advanced technological solutions;

Thirdly, creation of the system of stimuli for their implementation taking into account the multidirectional nature of economic interests of participants;

Fourthly, coordination of participants and adjustment in the operational mode, time of certain provisions and projects of the Program;

Fifthly, amendment of the system of education for satisfying demands in personnel for companies, scientific and creative teams participating in the formation of markets in the framework of the National technological initiative. 


\section{Results}

Practical implementation of "road map" is carried out by the start of concrete projects of the National technological initiative. At the same time, the project pool is mobile in its nature and is formed on the competitive basis taking into account results in the related fields, as well as the cyclical processes of development and implementation of the project pool [6]. The structure of the implemented projects has been formed as a result of the scientific discussion fully responding to the priority directions of the technological initiative. Now they embrace the following:

1) The market of services of intellectual energetics, and ecosystems of producers and consumers of energy (EnergyNet). The task of this direction is characterized as implementation of the whole project cycle up to seamless integration into common infrastructure and energy exchange;

2) The intellectual market of production and distribution of food and products with the client-oriented logistics (FoodNet). The task is to account real demands and diminish distance from producers to consumers of the food products;

3) The personal security systems (SafeNet), as the basis for satisfaction of the basic need in the life safety;

4) The personal medicine (HealthNet), that takes into account continuous-time state of health of each, and provides for the fast reaction and medical health;

5) The market of services based on aviation, space and pilotless vehicles (AeroNet) with a wide range of applications, in fact, in all sectors of industry, including remote sensing of the Earth, agriculture, search and rescue operations, suborbital tourism, etc.;

6) The global market for distributed intelligent systems for maritime transport management and technologies for the ocean (MariNet) as a basis for expanding resource basis for development and significant acceleration of the global resource turnover;

7) The market for drones and practice-oriented solutions based on them (AutoNet), that allows creating alternative transport system;

8) The market for decentralized financial systems and currencies (FinNet), that increase maneuvering and accumulative opportunities of the investment processes;

9) The market for information exchange of the next generation, the products and services of which are based on the knowledge about the brain and focused on the expanding resources of the brain (NeuroNet) that will contribute to capitalization of intellectual resources of the national economy.

\section{Discussion}

The strategy of the National technological initiative envisaged that the share of private investments to the long-term research programs should be at the level of $50 \%$ of total investment, and foreign investments to the Russian technological initiatives should reach the level of $10 \%$ of the targeted country's budget for research and development. In addition to that, by 2035 total expenses for science and technology should be increased to the level of $4 \%$ of GNP. Meanwhile, the incomes of Russian companies and universities to be obtained from the management of the intellectual property should achieve the level of at least $1 \%$ of the turnover on the global market [7]. In this case Russia would be able to join the Top-5 in the ranking on a number of specialists in the field of research and development.

Restructuring of the system of the state funding is envisaged for the achievement of the assigned goals in a long-term prospective. So, in 2017 the Government of Russia allocated 8.5 billion RUB for subsidizing costs for implementation of the road maps. In total, 12.5 billion RUB was reserved in the federal budget in 2017 for the purposes of implementation of activities of the National technological initiative. Of that, 2 billion RUB was used for 
financing centers of the National technological initiative created at educational and scientific organizations. The same amount was allocated for grants by the purposely created Foundation for promotion of innovation provided for research and development connected with implementation of the road maps [8]. Funding for 2018 and 2019 has also been formed in accordance with requirements of implementation of road maps and the Matrix of the National technological initiative (NTI Matrix). The latter links the stages of the program cycle with the system of supporting measures. Herewith, a large technological package embraces basic priorities of technological policy: big data, artificial intelligence, distributed registry system, quantum technologies, etc. that are, as a whole, the technologies of the Russian origin. In perspective, the technological package is supplemented with new and portable power sources, new production technologies, technologies of wireless communication, sensors and components of robotics, etc. Structuring of global challenges of science, projected onto a practical plane and formatted as megaprojects with participation of universities and scientific and technological centers is the basis of the Matrix. In addition to that, implementation block of the basic NTI Matrix incorporates a system of the resource accumulation, and special services: concierge service, development of intellectual property, promotion of consumers of the NTI companies, providing special conditions on the domestic market (quasi-monopolies), support for the strategic growth, tax system, a distributed registry of the NTI companies, comfort jurisdiction, marketing and supporting export, as well as support to promotion of the standards $[9,10]$. In the NTI Matrix, special attention is payed to the methods of identification and formation of intellectual resources. The priorities of science policy are outlined, methods of management of the career growth of the researchers are formalized, and, that is very important, priorities of the educational policy are reconsidered. A wide range of such tools as the extremums, Olympiads, contests, interest groups, trajectories, mentors, challenges, career, milieu, and networks, utilized in the managing regime, according to the creators of the Program will allow filling all technological trends by specialists.

However, focusing on selected advanced technologies, especially those of a production type, none of them alone can provide a strategic advantage in global markets. Only complex technological solutions that in a short run provide not only design, but production of products of the new generation capable to compete on the global markets are able to solve the assigned tasks. In the road maps, such solutions are elaborated by the Digital, Smart, Virtual Factories of the Future. At the same time, digital factories are seen as the systems of complex technological solutions for all stages from design to production, from a stage of research and planning to the creation of the Digital Mock-Up (DMU), a prototype or small series. "Smart" models of products on the basis of new paradigm of digital design and modelling are created on a digital factory.

"Smart" factories are the systems of complex technological solutions, distinctive features of which are high level of automation and robotics, excluding human factor and errors connected with this factor and leading to loss of quality. At the same time, virtual factories represent systems of complex technological solutions, integrating digital and (or) "smart" factories to a distributed network. Virtual factory envisages information systems of the enterprise management that allow developing and utilizing as a single object a virtual model of all organizational, technological, logistics and other processes at the level of global supply chains and (or) at the level of the distributed production assets.

However, a number of measures of supporting character is only drafted and requires elaboration in more details. It is not obvious due to what the investment activity of private business will increase? How the comfortable jurisdiction will be created and which measures will form the stimulating block of the Program?

Our analysis has shown that comfortable legal and investment milieu along with highly maneuvering budget policy are the background for the growth of business activity in all 
spheres of national economy, including innovation focusing on all investment programs [11]. Herewith, it is necessary to form a system with equal-weigh components for provision of complex solution for the issue of adequate milieu that is to include the following:

1) Regulatory support norms for technological initiatives as the key national priority;

2) Mechanism of investment protection, including foreign investments;

3) Mobilization mechanisms including measures of the targeted support, funding, guarantees, crowd-investing, etc.;

4) Mechanisms of enforcement, integrating organizational and economic measures, enforcing to implementation of requirements of provision of the technological development.

As has been shown by the analysis, measures of export support and promotion of new technologies into the economic practice cannot be performed by the outdated institutes. New formal and informal institutes are needed. Today, they are being discussed and initiated by the workforces of the National technological initiative. Herewith, it is worth mentioning that institutional support should take into account peculiarities of the most important applied fields of introduction of new technologies and capabilities of scientific tools (foresight approach, neurolinguistics programming, etc.) [12, 13, 14].

The study of the largest megaprojects of the new economy $[15,16,17]$ has indicated that they conditionally can be split on the following:

I. The construction projects:

1) The projects of the linear construction that include new pipelines, road, energy (networks), communal and other construction. The creation of new transportation corridors, such as automobile and railroads, etc., has a special significance.

2) The projects of the ground construction. Their spectrum is very wide: from sea ports to airports, from aqua-territorial complexes to gas transportation complexes, from production facilities of the defense nature to "smart towns", etc. [11];

II. The projects focused on liquidation of the infrastructural wear. Very lengthy investment break in the infrastructural construction does not leave any other options as to create new infrastructure on the basis of use of new technologies. That means, de facto, a renewal of infrastructure that is to be based on steady replacement of obsolete funds with new ones with utilization of innovations of the National technological initiative. It means that the project block of renewal and liquidation of infrastructure wear and tear should be included into the NTI Matrix. Being an individual practice-oriented task with the capacity of 4-5 trillion RUR annually, its implementation will require development of the specialized projects pool. Its content will determine not only the future scale of investments, but peculiarities of practical investment tools.

Currently an active discussion is being carried out around the choice of mechanisms of implementation of infrastructural projects [18]. These can be concession mechanisms, governmental orders, syndicated loans or a new infrastructure mortgage mechanism. Its advantage is in the fact that the principle of the double leverage can be implemented, that allow stimulating private investments and bond-type loans. Some elements of such approach can partially be used for the investment filling of the National technological initiative projects.

\section{Conclusion}

The suggested methodology does not require global restructuring of the financial management system, allows attracting available labor resources, and is an effective weapon in the fight against uncertainty. In addition to the dry mathematical apparatus, it pays attention to the expert estimates. Besides, it should be noted that this technique has very good flexibility, and can be used for solution of many tasks in the analysis of investment projects. 
As the main parameters by which projects are compared, it is permissible to use any criteria, and in unlimited quantities.

\section{References}

1. Message of the President of the Russian Federation to the Federal Assembly (http://ria.ru/trend/_message_Putin_04122014, 2018)

2. J. C. Narver, S. F. Slater, Journal of Mrketing, 54, 20-35 (1990)

3. World Economic Forum (http://www.weforum.org, 2018)

4. T. Wulf, P. Meissner, S. Stubner, Leipzig Graduate School of Management, 98, 981998 (2012)

5. Official site of the IX Gaidar forum "Russia and the World: Goals and Values" (http://gaidarforum.ru, 2018)

6. N. Yu. Yaskova, Bulletin of the Moscow State University of Economics and Finance, 6(105), 680-686 (2017)

7. National technological initiative (http://asi.ru/nti/, 2018)

8. Fund for Promoting Innovation (http://fasie.ru, 2018)

9. J. Coates, Technological Forecasting and Social Change, 71, 5 (2004)

10. M. Parra-Lancourt, Commodities and terms of trade from a really long-term perspective (Global Commodities Forum. Geneva, 2015)

11. N. Yu. Yaskova, D. M. Karasik. Scientific Review, 6, 115-119 (2013)

12. T. P. Alekseeva, N. Yu. Yaskova, P. N. Rodionov. The development of tools for the modernization of the building complex (Moscow, 2016)

13. L. Williams, W. Adams. Nanotechnology without secrets (Eksmo, Moscow, 2010)

14. R. Rohrbeck, Technological Forecasting \& Social Change, 78(2), 231-243 (2016)

15. V. S. Efimov, Siberia and the Far East in the 21st Century: problems and Development prospects (Siberian Federal University, Krasnoyarsk, 2017)

16. R. Vecchiato, C. Roveda, Technological Forecasting \& Social Change, 77(9), 15271539 (2010)

17. GM Crops, ISAAA Brief, 49 (2014)

18. XVII International Investment Forum "Sochi-2018” (http://forum-in-sochi.ru, 2018) 